\title{
Consciência fonológica: o efeito do seu treinamento no desenvolvimento da escrita em crianças pré-escolares
}

Effect of phonological awareness training on the development of preschool children's writing skills

\section{Cláudia Nascimento Guaraldo Justi Universidade Federal de Pernambuco Francis Ricardo dos Reis Justi Universidade Federal de Pernambuco}

\begin{abstract}
Phonological awareness has been pointed out as one of the most important variables in the development of reading and writing. The present study investigated the effects of phonological awareness training in the development of kindergarten's writing skills. The training was applied to 20 kindergartens, which were allocated to 2 experimental groups and 1 control group. In one experimental group training was developed through a computer program, and in another experimental group training was developed through the use of cards. Statistical analysis and measures of effect size $(d)$ demonstrated the training efficacy in writing development. This efficacy was independent of the training method (computer or cards). These results suggest the need of developing phonological awareness skills in kindergartens.
\end{abstract}

Keywords

Phonological awareness; Writing; Education; Computer. 


\section{Resumo}

A consciência fonológica tem sido apontada como uma das principais variáveis a influenciar o desenvolvimento da leitura e da escrita. Este estudo investigou o treinamento dessa habilidade no desenvolvimento da escrita em crianças pré-escolares. Participaram dessa pesquisa 20 crianças pré-escolares que foram divididas em três grupos, sendo dois deles experimentais e um controle. O treinamento foi desenvolvido por meio do uso de computadores ( $1^{\circ}$ grupo experimental) e de cartões $\left(2^{\circ}\right.$ grupo experimental). Análises estatísticas e o cálculo da magnitude do efeito $(d)$ evidenciaram que o treinamento da consciência fonológica foi bastante eficaz no desenvolvimento da escrita, independentemente do instrumento utilizado no treinamento. Esses dados sugerem a importância da realização de atividades voltadas para o desenvolvimento dessa habilidade em crianças pré-escolares.

\section{Palavras-chave}

Consciência fonológica; Escrita; Educação; Computador. 


\section{INTRODUÇÃO}

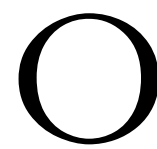

aprendizado da leitura e da escrita pode ser considerado um dos requisitos mais importantes em uma sociedade como a nossa, pois em um meio onde a maior parte das informações é transmitida via mídia impressa, pelo menos no que diz respeito à educação formal, essas habilidades se tornam indispensáveis. Nesse sentido, pesquisas sobre as habilidades necessárias para esse aprendizado são de grande relevância. O português brasileiro é um sistema de escrita ortográfico-alfabético (MASSINI-CAGLIARI; CAGLIARI, 1999). Entre outros aprendizados necessários, para que uma criança desenvolva a habilidade de ler e escrever em um sistema de escrita alfabético, é importante que ela aprenda que letras, geralmente, representam fonemas. Um dos fatores que auxilia nesse aprendizado é a aquisição do princípio alfabético. Esse princípio refere-se à idéia de que símbolos escritos (letras) estão associados a fonemas (menor elemento constitutivo da cadeia falada que permite fazer distinções semânticas - Morais, 1996).

A noção de fonema, necessária para compreender o princípio alfabético, não é óbvia para as crianças. De acordo com Morais (1996) e Barrera (1999), a tendência que muitos pesquisadores têm em julgar ser evidente para todos que a fala é uma combinação de pequenos sons, ou seja, que todo mundo sabe que 'mar' e 'bar' têm cada um três sons elementares e que só se diferem pelo primeiro, não é tão evidente assim. A habilidade de se refletir sobre a estrutura sonora da linguagem falada é conhecida na literatura como consciência fonológica, um dos componentes do processamento fonológico (CARDOSO-MARTINS, 1991).

O termo 'processamento fonológico' refere-se ao uso de informação sobre a fonologia no processamento da linguagem oral 
e escrita (WAGNER; TORGESEN; LAUGHON; SIMMONS; RASHOTTE, 1993). Em geral, o termo é usado para se referir às atividades mentais envolvidas na leitura e/ou em sua aprendizagem que envolvem o acesso, a estocagem ou a manipulação de informação de natureza fonológica (EDWARDS; WALLEY; BALL, 2003). Os resultados de vários estudos sugerem que o desempenho de crianças em idade pré-escolar em tarefas de processamento fonológico correlaciona-se com sua habilidade de ler anos mais tarde (BRYANT; BRADLEY, 1987; CARDOSO-MARTINS, 1995a; MANN, 1984; MANN; LIBERMAN, 1984; TORGESEN; WAGNER; RASHOTTE; BURGESS; HECHT, 1997; WAGNER et al, 1993; WAGNER; TORGESEN; RASHOTTE, 1994; WAGNER; TORGESEN; RASHOTTE; HECHT; BARKER; BURGESS; DNAHUE; GARON, 1997).

Segundo Wagner et al (1993), três processos fonológicos têm sido investigados ao longo dos anos: a consciência fonológica, isto é, a habilidade de perceber e manipular os sons das palavras faladas; a codificação fonológica na memória de trabalbo, isto é, a codificação de informação de natureza não-fonológica em um sistema de representação baseado no som para armazenamento eficiente na memória de trabalho durante o processamento; e a recuperação de códigos fonológicos na memória de longo prazo, isto é, a recuperação da forma fonológica de palavras na memória de longo prazo.

Em suma, o processamento fonológico refere-se à habilidade de usar o sistema sonoro de nossa língua para processar informações orais e escritas. A consciência fonológica é uma das habilidades componentes do processamento fonológico que mais tem sido pesquisada e, de uma maneira geral, é apontada como sendo a chave para o desenvolvimento da leitura e da escrita. Com efeito, os resultados de vários estudos apontam uma relação estreita entre a consciência fonológica e a habilidade de leitura. Isso é verdade até para estudos controlando o efeito de diferenças em variáveis potencialmente importantes, como a inteligência, o vocabulário, a memória e a classe socioeconômica. Quanto melhor as crianças desempenham as tarefas de consciência fonológica, mais rápido elas aprendem a ler e a 
escrever (BRYANT; MACLEAN; BRADLEY; CROSSLAND, 1990; WAGNER; TORGESEN, 1987; WAGNER; TORGESEN; RASHOTTE, 1994).

Tendo a consciência fonológica uma relação tão importante com o aprendizado da leitura e da escrita, é importante abordar, de forma mais compreensiva, esse construto.

\section{O QUE É A CONSCIÊNCIA FONOLÓGICA?}

Em 1973, Isabelle Liberman propôs que o obstáculo inicial na aprendizagem da leitura decorre da necessidade de o leitor principiante se tornar consciente de que as palavras podem ser analisadas em termos de seqüências de fonemas. Segundo a pesquisadora, o que torna difícil o aprendizado da leitura é o fato de que os gestos articulatórios que compõem as consoantes e as vogais são intrinsecamente justapostos na articulação da sílaba. Como resultado, os fonemas não podem ser recuperados através de uma simples segmentação linear do sinal acústico, o que, para Liberman, é um fator de dificuldade, pois a segmentação fonêmica é muito importante para o desenvolvimento da leitura em ortografias alfabéticas. Dessa forma, segundo a pesquisadora, podemos pensar que "aprender a ler é difícil porque falar é fácil”, pois a coarticulação que nos ajuda a falar rapidamente, dificulta a nossa descoberta dos segmentos fonêmicos nas palavras faladas (PENNINGTON, p. 18, 2003).

Desde a década de 1970, com os trabalhos de Liberman, a consciência fonológica tem sido vista como a chave para explicar como as crianças aprendem a relação entre as palavras faladas e as palavras escritas. Snowling e Hulme definiram 'consciência fonológica' como sendo a "habilidade de refletir, explicitamente, sobre a estrutura sonora das palavras faladas" (1993, p.726). De acordo com Castles e Coltheart (2004), o componente 'consciência' é tão importante para a definição quanto o componente 'fonológico', pois a habilidade não se refere à discriminação dos sons da fala (tais como na percepção da fala), mas a um processo explícito e deliberado sobre eles. 
Partindo do pressuposto de que a consciência fonológica "habilidade de refletir, explicitamente, sobre a estrutura sonora das palavras faladas" (SNOWLING e HULME, p. 726, 1993) - é uma forma de metalinguagem, torna-se mais compreensível, portanto, a dificuldade das crianças no desempenho desse tipo de tarefa. Byrne (1995) apresenta uma reflexão bastante interessante para exemplificar o quanto pode ser difícil tornar objeto do pensamento algo que podemos fazer automaticamente. Por exemplo, embora possamos engatinhar no chão sem problemas, temos dificuldade em descrever a seqüência de movimentos de braços e pernas realizados no ato de engatinhar. Segundo Byrne, a mesma dificuldade está presente na consciência metacognitiva da linguagem: "em geral, as coisas que podemos fazer facilmente são difíceis de serem objetos do pensamento" (1995, p. 42).

Com base no pressuposto de que a consciência fonológica é uma forma de metaconhecimento lingüístico e se refere à habilidade para executar operações mentais sobre a fala, ou seja, refletir conscientemente sobre a estrutura sonora da fala, torna-se mais compreensível, portanto, a não obviedade dessa habilidade para as crianças.

Estudos realizados por Carraher e Rego (citado em MALUF e BARRERA, 1997) têm sugerido que a base cognitiva necessária para que a criança possa perceber as palavras, enquanto seqüências de sons a serem representados graficamente, estaria na superação do realismo nominal. O realismo nominal refere-se a uma confusão estabelecida pela criança pequena entre significantes e significados, com tendência a atribuir às palavras características daquilo que elas representam, devido à dificuldade em perceber o caráter convencional e arbitrário dos nomes. A superação do realismo nominal possibilitaria, assim, a completa distinção entre significantes e significados e a conseqüente compreensão das palavras enquanto signos verbais arbitrários, capazes de serem representados graficamente, facilitando a aquisição da escrita (DEFIOR, 1996). Em um artigo bastante recente, Stuart (2005) menciona que, se a habilidade de se descentrar do significado da palavra e focar na sua estrutura fosse interpretada dentro do arcabouço teórico piagetiano, as crianças precisariam ter 
alcançado o estágio operacional concreto para desempenhar tarefas de consciência fonêmica com sucesso. Em um estudo realizado por Schreuder e van Bom (1989, citado em STUART, 2005), essa hipótese foi avaliada tendo como amostra crianças alemãs, e os pesquisadores encontraram evidências indo a favor da interpretação piagetiana (Cf. STUART, 2005, para mais detalhes). No entanto, os resultados do estudo de Cardoso-Martins e Duarte (1994) sugerem que os diferentes tipos de operações fonológicas requeridas em tarefas comumente usadas para avaliar essa questão afetam o desempenho das crianças. As pesquisadoras utilizaram duas tarefas diferentes para avaliar a habilidade de crianças pré-escolares se desprenderem do significado da palavra e focar a atenção nas propriedades fonológicas dela. Em uma dessas tarefas, as pesquisadoras enunciavam duas palavras e avaliavam a habilidade da criança de comparar o tamanho das palavras, para pares nos quais o comprimento da palavra e o tamanho do objeto a que ela se referia eram incongruentes (trem - telefone). Já a tarefa de 'similaridade da palavra' avaliava a habilidade da criança de identificar, entre duas palavras diferentes, aquela que era mais parecida com a palavra-alvo. Enquanto uma das palavras rimava com a palavra-alvo, a outra era semanticamente relacionada a ela. De uma forma geral, as crianças pré-escolares conseguiram se desprender mais do significado das palavras e se atentarem para as propriedades fonológicas delas na tarefa de 'similaridade da palavra' do que na tarefa de 'tamanho da palavra', evidenciando, dessa forma, que o tipo de tarefa escolhida pode influenciar o desempenho das crianças.

Como ressaltamos, a habilidade de refletir sobre os constituintes sonoros da fala não é uma tarefa simples para as crianças. A consciência fonológica não se caracteriza por ser um bloco monolítico, uma entidade homogênea, algo que alguém tenha ou não, pois se refere à consciência de diferentes unidades lingüísticas (ROAZZI; DOWKER, 1989). O termo 'fonológico' refere-se aos sons dentro das palavras e inclui não somente fonemas, mas também maiores unidades de som. De acordo com Cardoso-Martins (1996), podemos pensar nas dificuldades encontradas pelas crianças no desempenho 
das tarefas de consciência fonológica de duas formas diferentes: a) dificuldade devido à unidade de som observada; b) dificuldade devido à demanda cognitiva da tarefa.

No que diz respeito à dificuldade devido à unidade fonológica envolvida na tarefa, podemos pensar que há três níveis de consciência fonológica implicados nas análises da maioria das linguagens: a consciência silábica; a consciência das unidades intra-silábicas: rima ${ }^{1}$ e ataque $;^{2}$ e a consciência fonêmica. A consciência silábica refere-se ao reconhecimento de que as palavras faladas podem se subdividir em unidades menores, no caso, as sílabas (a palavra BANANA possui três sílabas: BA-NA-NA). A consciência da rima e do ataque referese ao reconhecimento de que a sílaba pode ser subdividida em duas unidades principais: o ataque e a rima. Por exemplo, na palavra MÃO, o ataque é / $\mathrm{M}$ / e a rima é /ÃO/. A consciência fonêmica refere-se ao reconhecimento de que as palavras podem se subdividir em unidades ainda menores do que o ataque e a rima: os fonemas. A forma falada da palavra MÃO consiste em três fonemas $/ \mathrm{m} / \tilde{a} / \mathrm{w} /$ (CHEN; ANDERSON; LI; HAO; WU; SHU, 2004). Há evidência de que a dificuldade encontrada pelas crianças no desempenho das tarefas de consciência fonológica varia de acordo com a unidade fonológica envolvida em cada tarefa. Tarefas que envolvem a manipulação e a segmentação de silabas, ${ }^{3}$ por exemplo, são menos complexas do que tarefas que implicam a manipulação e a segmentação de fonemas. ${ }^{4}$

No que diz respeito à demanda cognitiva da tarefa utilizada para avaliar a consciência fonológica, existe evidência de que as tarefas que avaliam a habilidade de detectar semelhanças e diferenças fonológicas entre palavras diferentes têm uma demanda cognitiva menor do que as tarefas que exigem a habilidade de segmentação e manipulação de fonemas. (Cf. CARDOSO-MARTINS, 1996). 


\section{A CONSCIÊNCIA FONOLÓGICA E O DESENVOLVIMENTO DA LEITURA E DA ESCRITA}

A relação existente entre a consciência fonológica e o desenvolvimento da leitura e escrita pode ser interpretada de, pelo menos, três formas. Uma das primeiras interpretações propõe que a consciência fonológica desempenha um papel causal na aquisição tanto da leitura quanto da escrita, capacitando as aquisições de habilidades precoces das duas. A formulação original dessa teoria focou-se no nível do fonema. Seu principal argumento é o de que, desde que letras, geralmente, representam fonemas nas línguas alfabéticas, a criança precisa tornar-se consciente dos segmentos fonêmicos nas palavras faladas, antes de aprender sobre as correspondências letrafonema (LIBERMAN, 1973). Mais recentemente, outros têm argumentado que a consciência de unidades maiores da fala, tais como rimas (a palavra GATO rima com PATO, assim como BOLA com GOLA), poderia auxiliar a criança a mapear esses sons, que ocorrem com freqüência em seqüências de letras, tais como / ola/ ou /ato/ (GOSWAMI e BRYANT, 1990). Para esses autores, as crianças, através de analogias, logo compreendem que palavras que rimam compartilham letras em comum e utilizam esse conhecimento para ler palavras desconhecidas que compartilham a mesma seqüência final de letras das palavras conhecidas. Para Bryant e Bradley (1987), quando alguém se dá conta de que palavras rimam, está dissecando os sons dessas palavras. No momento que se sabe que 'gato' e 'rato' têm um som em comum e que este som é 'ato', decompõe-se cada uma dessas duas palavras em menores unidades de som. Assim sendo, a criança que compreende rima, deve saber algo sobre os sons constituintes das palavras. A rima é a base dos jogos de palavras e, naturalmente, das cantigas de roda, sendo, portanto, parte marcante do começo da vida das crianças. Desde bastante pequenas, as crianças dão todos os sinais de apreciar cantigas e jingles que envolvem rimas e parecem lembrá-los muito bem. Prestam atenção em brinquedos e simples brincadeiras em que rimar palavras tem um papel importante. Segundo esses mesmos autores, se as crianças absorvem as rimas, 
devem, de alguma maneira, ser também conscientes dos sons da fala. E uma vez que se trata de crianças muito pequenas - que ainda estão longe de começar a ler - está implícito que esse tipo de consciência precede a leitura por um período de tempo significativo e que, ao estimularmos a sensibilidade aos sons das palavras, às rimas, estaremos 'preparando' a criança para a aquisição da leitura e da escrita.

Para avaliar a hipótese de que a consciência fonológica é precursora da aquisição da leitura, Bryant e Bradley (1987) realizaram um estudo longitudinal na Inglaterra com 400 crianças pré-escolares. No início do estudo, nenhuma das crianças havia começado a ler. A avaliação da consciência fonológica consistia em ministrar séries de tarefas de rima e aliteração: as crianças escutavam três ou quatro palavras, duas ou três das quais tinham um som em comum. As crianças tinham de ouvir as palavras e indicar aos pesquisadores qual delas destoava das demais. A posição do som na palavra-alvo variava. Em alguns itens estava no final (por exemplo: 'pin', 'win', 'sit'), em outros, no meio (por exemplo: 'pot', 'cat', 'bat') e, em alguns, no início (por exemplo: ' $\boldsymbol{b}$ ill, ' $p i g$, 'pin'). Nos dois primeiros casos, as crianças tinham de indicar quais palavras rimavam; no terceiro, tinham de se dar conta da aliteração. Ao atingirem a idade de oito ou nove anos, elas foram novamente submetidas à avaliação do nível de desenvolvimento da leitura. Os escores das crianças nos testes iniciais de rima e aliteração predisseram seu progresso na leitura e no soletrar três ou quatro anos mais tarde. A relação se manteve constante mesmo após os autores haverem controlado os efeitos de variações na inteligência, na memória e na educação materna.

É importante salientar que tanto a proposta de Liberman, no que se refere aos fonemas, quanto a de Bryant e Bradley, no que se refere à rima, não é de que a consciência de unidades fonológicas faz com que a criança seja capaz de ler, mas que permita um melhor aprendizado da leitura em algum tempo mais tarde.

Consistente também com essa posição, há demonstrações experimentais e longitudinais de que o treinamento da consciência fonológica das crianças afeta positivamente a leitura e a escrita 
(BRYANT e BRADLEY, 1987; BYRNE, 1995; CAPOVILLA e CAPOVILLA, 2000; CARDOSO-MARTINS, 1995b).

De acordo com uma segunda posição, é o processo de aprender a ler e escrever, por si mesmo, que alerta o aprendiz para a relevância dos segmentos fonológicos na linguagem. Por exemplo, Morais e seus colaboradores (1996) avaliaram a consciência fonológica de adultos portugueses iletrados, que jamais tinham aprendido a ler e a escrever, comparando-os a ex-iletrados, isto é, pessoas que tinham aprendido a ler e a escrever na idade adulta, em classes de alfabetização. Os sujeitos foram submetidos a tarefas de adição e subtração de fonemas e sílabas. Segundo o pesquisador, os adultos iletrados foram incapazes de realizar as tarefas que envolviam adição e subtração de fonemas (não se tratava de uma dificuldade de compreender a operação de subtração, pois a maioria dos iletrados conseguira êxito nas tarefas de subtração e adição de sílaba). Em compensação, a grande maioria dos ex-iletrados conseguiu realizar a subtração de fonemas.

Os resultados de estudos translingüísticos recentes são também consistentes com essa interpretação. Mann e Wimmer (2002) compararam habilidades de consciência fonológica de pré-escolares americanos que aprendem os nomes e os sons das letras antes de entrarem na escola, com pré-escolares alemães que, em geral, aprendem os nomes e os sons das letras apenas na primeira série. As crianças americanas apresentaram um desempenho superior ao das crianças alemãs, o que levou os autores a concluir que a consciência fonêmica se desenvolve, primariamente, como uma conseqüência da exposição ao ensino formal da leitura.

A terceira posição e a mais aceita atualmente, segundo Barrera (2003), é a que concebe tal relação como sendo interativa: ambos os fatores - desenvolvimento da leitura e da escrita e desenvolvimento da consciência fonológica - influenciando-se mutuamente (BOWEY, 1994; MANRIQUE; SIGNORINI, 1988; MORAIS; ALEGRIA; CONTENT, 1987; CASTLES; HOLMES; NEATH; KINOSHITA, 2003). Dessa forma, embora não se possa negar que a própria situação de ensino/ aprendizagem da linguagem escrita leva os aprendizes a focarem sua 
atenção nos segmentos sonoros da linguagem, sobretudo no que se refere à identificação e manipulação dos fonemas (MORAIS, 1996), é possível supor, também, que o nível de consciência fonológica adquirido anteriormente a esse processo de instrução formal, sobretudo no que se refere às sílabas e a outras unidades suprasegmentares, possa desempenhar um papel facilitador para o processo de alfabetização (GOSWAMI; BRYANT, 1990; BRYANT; BRADLEY, 1987).

Em suma, enquanto, para alguns pesquisadores, a habilidade de refletir conscientemente sobre os sons das palavras facilitaria o desenvolvimento da leitura e da escrita, para outros, o contrário é que seria a realidade, ou seja, o ensino formal das habilidades de ler e escrever é que facilitaria o desenvolvimento da consciência fonológica. Pesquisadores de ambos os lados possuem evidências advindas de investigações científicas para suas interpretações e é, exatamente, esses achados que têm dado suporte à conclusão de que há uma relação recíproca entre consciência fonológica e aquisição da leitura e da escrita.

Levando-se em consideração a importância apontada em pesquisas anteriores sobre a possível relação entre a consciência fonológica e o desenvolvimento da escrita, o presente trabalho teve como objetivos primordiais: 1) levar a cabo um programa de treinamento da consciência fonológica (por meio do uso de computadores e por meio de cartões) e observar as possíveis alterações na escrita; 2) avaliar se o computador é um dispositivo eficaz para ser utilizado na estimulação da consciência fonológica; e 3) uma vez estabelecido o efeito do treinamento na consciência fonológica e sua influência na escrita, prover o leitor de algumas estimativas do quão forte é esse efeito. Para isso, seguindo as recomendações de Cohen (1977; 1994), calculamos a magnitude do efeito do treinamento $(d)$, tanto para a consciência fonológica, quanto para a repercussão do treinamento dessa na escrita.

O presente trabalho assentou-se na necessidade de investigarmos um possível método de intervenção que visasse à estimulação da 
consciência fonológica, tendo em vista a sua possível influência no desenvolvimento da escrita. Também dentro dessa vertente mais pragmática, investigamos se o computador - instrumento que pode ser um facilitador do trabalho de psicólogos e professores e que atrai a atenção das crianças pelos seus recursos audiovisuais - é um instrumento efetivo nesse processo de estimulação. Além disso, esse estudo pode servir ao planejamento de trabalhos posteriores, pois, ao relatar as estimativas da magnitude do efeito, permite que futuros investigadores possam usar esses dados para estimarem o tamanho de suas amostras.

\section{METODOLOGIA}

Trata-se de uma pesquisa experimental realizada em uma escola particular localizada na zona urbana de Juiz de Fora - MG. Cabe assinalar que a metodologia de ensino da escola era inspirada na proposta construtivista. Assim sendo, pressupunha-se que, interagindo com a escrita, a criança iria construir o seu conhecimento, elaborando hipóteses a respeito da escrita e, com isso, aprendendo a ler e a escrever numa descoberta progressiva. Nesse sentido, a escola não enfatizava o desenvolvimento das habilidades de codificação e decodificação.

Esse estudo foi dividido em duas partes. A primeira parte consistiu na aplicação de testes psicológicos visando à seleção e à divisão dos participantes do experimento em três grupos homogêneos. A segunda parte consistiu no treinamento da consciência fonológica nos dois grupos experimentais (treinamento com computador e treinamento manual).

\section{Amostra}

Participaram da primeira parte deste estudo 32 crianças, de classe média, que cursavam o $2^{\circ}$ ou o $3^{\circ}$ período da pré-escola, com idades entre 4 e 6 anos, sendo que a média de idade calculada em 
meses equivale a 68 meses (cinco anos e meio aproximadamente). Dessas 32 crianças, foram selecionadas 20 para participarem do estudo. O critério de seleção foi o nível de desenvolvimento da escrita em que se encontravam no momento da pré-testagem.

As 20 crianças selecionadas foram distribuídas, homogeneamente, de acordo com seus escores nos testes de recepção auditiva (subteste do ITPA), memória seqüencial auditiva (subteste do ITPA), maturidade intelectual (Escala de maturidade mental Colúmbia) e resultados da avaliação da consciência fonológica e do nível de desenvolvimento da escrita (segundo FERREIRO e TEBEROSKY, 1986), totalizando sete crianças em cada grupo experimental e seis no grupo controle.

Todas as 20 crianças que participaram do treinamento da consciência fonológica encontravam-se no período pré-silábico do desenvolvimento da escrita. É importante assinalar que essas crianças já tinham uma concepção geral do que seria a escrita. Por exemplo, elas tinham conhecimento de que escrever envolvia traçar símbolos em uma superfície material; elas sabiam que a escrita se dava da esquerda para a direita; elas representavam a escrita com letras, mas ainda sem que essas apresentassem qualquer relação com o aspecto sonoro das palavras.

\section{Instrumentos}

Tarefa de escrita: ditado formado por 10 itens: oito palavras que variavam quanto ao comprimento e duas não-palavras.

Escala de Maturidade Mental Colúmbia: é um teste de inteligência não verbal que mede a capacidade de raciocínio geral. É indicado para crianças de 3 anos e meio a 9 anos e 11 meses.

ITPA (Teste Illinois de habilidades psicolingüísticas): é um teste que avalia habilidades psicolingüísticas. Apenas dois dos subtestes foram aplicados: recepção auditiva e memória seqüencial auditiva.

Software de avaliação da consciência fonológica: para avaliar o nível de consciência fonológica, desenvolvemos um software que foi baseado no 'Oddity Test' elaborado por Bryant e Bradley (1987). 
Esse teste consistia em apresentar às crianças três palavras, sendo que duas delas tinham o mesmo som final e a outra tinha um som diferente (ex.: 'cat', 'bat', ' $d o g$ '). Após a apresentação dessas palavras, era solicitado à criança que indicasse aquela que tivesse o som final mais diferente. Cabe ressaltar que Bryant e Bradley não utilizaram o computador como um recurso de avaliação.

A nossa versão desse teste consistiu em 15 páginas do programa de autoria denominado Asymetrix Toolbook II Instructor (ASYMETRIX CORPORATION, 1996). Este software é bastante utilizado em laboratórios de psicologia experimental, pois permite a criação de outros softwares a partir dele. Logo na primeira página, a fim de que a criança se familiarizasse com o dispositivo e se sentisse mais à vontade para realizar as atividades propostas, era apresentada uma breve saudação: "Olá, amiguinho! Chegou a hora de nós trabalharmos um pouquinho juntos! Você verá o quanto pode ser gostoso descobrir os sons das palavrinhas! Vamos começar?". Assim que ela percebia que estava preparada para iniciar, clicava em cima do botão 'ok' e uma gravação de som lhe solicitava que digitasse o seu nome: "Qual o seu nome? Digite o seu nome, por favor". Após digitar, a criança deveria clicar no botão 'ok' para passar para a página subseqüente, na qual recebia a seguinte instrução: "Vou falar três palavrinhas para você, duas têm o som final parecido e a outra tem o som diferente. Clique sobre a que tiver o som final mais diferente". Automaticamente abria-se uma nova página em que eram apresentadas três figuras. Ao enunciar a palavra, a figura correspondente era destacada concomitantemente. Com o auxílio do mouse, a criança clicava sobre a figura que ela acreditava possuir o nome com o som final mais diferente entre os três e, automaticamente, passava para a página posterior. As demais páginas seguiam o mesmo procedimento, variando apenas as palavras e as respectivas figuras apresentadas às crianças. Como se tratava de um software de avaliação, não era permitido às crianças fazer tentativas. Somente nas duas primeiras páginas, por se tratar de itens-treino, eram emitidos feedbacks para as crianças. 
Softwares de treinamento da consciência fonológica: para o treinamento da consciência fonológica, desenvolvemos no computador sete softwares, com o auxílio do mesmo programa de autoria. Cada um dos softwares era composto de seis tipos de atividades diferentes, as quais serão descritas a seguir.

Os primeiros cinco programas elaborados foram constituídos de palavras com a terminação sonora 'ato' e as palavras-chave foram: gato, rato, jato, pato e mato. Os outros dois buscavam treinar os sons 'ola' e 'ama', sendo as suas palavras principais gola e cama.

O treinamento seguia esta ordem:

1) A primeira tarefa consistiu na estimulação da identificação de rimas, na qual cinco figuras eram apresentadas, uma no centro da tela do computador (ex.: pato) e as outras distribuídas pelas laterais da página (ex.: bebê, pilha, jato, cesta). A criança ouvia a seguinte instrução emitida pelo computador: “... Preste atenção para você poder entender. Observe o som da palavrinha que será apresentada primeiro. Qual das outras palavrinhas que serão apresentadas tem o som mais parecido com o dela? Clique sobre ela". O objetivo era que a criança clicasse sobre a figura que possuía o nome com o som final mais parecido com o da palavra alvo (ex.: se a palavra-alvo era pato, a criança deveria clicar na figura de um jato). Como se tratava de um software de treinamento, após cada resposta, a criança ouvia se sua resposta estava correta ou incorreta e por quê. Se a resposta estava incorreta, ela ouvia a explicação e tentava novamente para poder passar para a próxima página do programa.

2) Na segunda tarefa, era fornecida à criança uma figura central (ex.: pato) com sua respectiva grafia e pronúncia. Logo abaixo, estavam escritas quatro outras palavras (ex.: reta, chuva, tato e vida). Era solicitado à criança que escolhesse, entre as quatro palavras que haviam sido pronunciadas, aquela que possuía o som final mais parecido com o da palavra central (pato). Cabe mencionar que a criança podia ouvir as palavras serem pronunciadas quantas vezes quisesse, bastava clicar o botão 
específico (orientada pelo experimentador que desempenhou o papel de mediador entre o programa de computador e a criança). Como podemos observar, a identificação de rimas continua a ser estimulada; no entanto, um novo dado se introduz: a grafia das palavras. Esse procedimento foi efetuado tendo em vista os estudos de Vernon (1998) que apontam para a importância de, ao estimularmos a sensibilidade à rima, apresentarmos as letras pertencentes ao sistema de escrita alfabético, pois, segundo a pesquisadora, esse procedimento é imprescindivel para que a criança faça uma analogia entre a escrita das palavras e os sons que a constituem.

3) Tendo como objetivo permitir à criança manipular o alfabeto visando à escrita de palavras que possuem a grafia final semelhante (palavras que rimam), a terceira tarefa foi elaborada. Nessa tarefa, a seguinte instrução era fornecida: "Observe a maneira correta de se escrever a palavrinha que será apresentada e escreva ela de novo no retângulo que estará logo abaixo. Agora, é a sua vez de colocar os dedinhos no teclado! Vá em frente!" Assim sendo, na presença da figura de um pato, com a sua pronúncia apresentada e a grafia reproduzida logo abaixo, a criança a reescrevia em um espaço indicado para isso.

4) Na quarta tarefa, a criança deveria escrever a palavra central trabalhada no programa - 'pato' - mas agora sem o auxílio do modelo. Abaixo da figura de um pato, havia quatro pequenos retângulos nos quais a criança deveria colocar cada letra correspondente para a escrita da palavra em questão. Na parte inferior da página, ela encontrava o alfabeto para lhe servir de auxílio. Após a escrita da palavra, a criança recebia um feedback; caso a palavra estivesse correta, a figura de um pato cedia lugar para a figura de um gato e a criança deveria alterar a escrita anterior para torná-la adequada à figura atual (as figuras jato, mato e rato vieram posteriormente).

Esse tipo de atividade, além de conscientizar as crianças de que as palavras são formadas por letras, tem o objetivo de auxiliá-las a 
perceber que poucas modificações são necessárias quando se quer escrever palavras que rimam, ou seja, que compartilham o mesmo som final.

5) A quinta tarefa apresentava uma história simples, composta de várias palavras com a mesma rima. Era dito à criança: "Gosta de histórias? Na historinha que segue você terá que preencher os retângulos com os nomes correspondentes às figurinhas que estão logo acima". A leitura da história era feita logo após a instrução, também utilizando o recurso sonoro do computador. Nesta página, além do botão de correção e de instrução, também eram fornecidas todas as palavras que a criança deveria escrever.

Este exercício possuía o mesmo objetivo do anterior. $\mathrm{O}$ experimentador transmitia à criança a informação de que a história estava incompleta e só com a ajuda dela é que a história poderia ser terminada de ser escrita.

6) O último exercício oferecia a seguinte informação: "Este exercício é muito legal!". Basta você clicar no nome da figurinha que aparecerá na tela!”. Assim, a criança teria que optar, entre cinco palavras, por aquela que correspondia à figura que estava ao lado. A primeira figura se tratava da palavra-chave do programa, 'pato', nas quatro páginas que seguiam, outras palavras, com o mesmo som final, eram apresentadas. Como feedback, havia os sons: "Oh, oh!", que permitiam à criança que reparasse o seu erro e, para o acerto, som de aplausos eram ouvidos.

Esse exercício foi elaborado de forma que todas as palavras terminadas em 'ato', trabalhadas nos programas de estimulação da consciência fonológica, fossem dispostas uma embaixo da outra, para que a visualização facilitasse a percepção de que apenas a troca de um único som seria suficiente para mudar o sentido e a grafia de uma palavra.

Na página final do livro, diante do desenho de uma garotinha, a criança escutava: "Amiguinho, por hoje é só! Gostei muito de fazer estas atividades com você! Até a próxima!". 
Treinamento com cartões - método tradicional: para o treinamento manual, o procedimento foi semelhante, no entanto não se dispunha dos recursos audiovisuais do computador. Desta forma, a tarefa era proposta por intermédio de cartões de papel com figuras, palavras, letras, e de instrução oral do experimentador. É importante mencionar que os cartões com as figuras, utilizados no treinamento manual, eram a reprodução das figuras utilizadas no software. Nós apenas imprimimos e plastificamos, para evitar que a diferença entre as figuras (cores, formas, tamanhos) utilizadas no grupo experimental I - treinamento com o auxílio do software - e as figuras utilizadas no grupo experimental II - treinamento manual, com auxílio de cartões pudesse afetar a resposta das crianças.

\section{PROCEDIMENTOS}

Primeiramente elaboramos um software com tarefas de identificação de rimas para avaliar a consciência fonológica das crianças, bem como sete outros softwares para a estimulação dessa habilidade. Para isso, utilizamos o programa de autoria denominado Asymetrix Toolbook II Instructor (ASYMETRIX CORPORATION, 1996).

Após a construção dos softwares e a autorização da escola e dos pais das crianças, demos início ao processo de avaliação em que consistiu a primeira parte de nosso estudo. Em sessões individuais realizadas na própria escola, as crianças foram avaliadas quanto à recepção auditiva (subteste do ITPA), memória seqüencial auditiva (subteste do ITPA) e maturidade intelectual (Escala de maturidade mental Colúmbia). Posteriormente, aplicamos o software de avaliação da consciência fonológica e, logo após, pedimos às crianças que realizassem um ditado composto por dez palavras, as quais variavam quanto ao número de sílabas. Entre as dez palavras do ditado, duas eram não-palavras (seqüências de letras, construídas com estruturas ortográficas possíveis em português, mas não associadas a nenhum significado). O ditado foi avaliado de acordo com os níveis de 
desenvolvimento da escrita proposto por Ferreiro e Teberosky (1986). ${ }^{5}$ Os resultados dessa pré-testagem nos possibilitaram a distribuição das crianças em três grupos homogêneos (TAB. 1), a fim de que pudéssemos dar início à segunda parte dessa pesquisa: o treinamento da consciência fonológica.

TABELA 1

Média e desvio-padrão dos escores de consciência fonológica, memória seqüencial auditiva, recepção auditiva e maturidade intelectual por grupo.

\begin{tabular}{|c|c|c|c|c|c|c|}
\hline & \multicolumn{2}{|c|}{ Grupo I } & \multicolumn{2}{|c|}{ Grupo II } & \multicolumn{2}{|c|}{ Grupo III } \\
\hline & Média & d.p & Média & d.p & Média & d.p \\
\hline $\mathbf{N}$ & 7 & & 7 & & 6 & \\
\hline Memória & 22,1 & $(8,7)$ & 21,5 & $(8,8)$ & 21,6 & (10) \\
\hline Recepção auditiva & 33,2 & $(3,3)$ & 33,2 & $(2,0)$ & 32,3 & $(2,4)$ \\
\hline Maturidade intelectual & 113,2 & $(11,0)$ & 110,2 & $(\mathbf{1 1 , 5 )}$ & 113 & $(8,7)$ \\
\hline Consciência fonológica & 6,0 & $(3,4)$ & 5,8 & $(2,5)$ & 5,3 & $(3,7)$ \\
\hline
\end{tabular}

Obs.: Grupo I - treino com computador; Grupo II - treino com cartões; Grupo III - controle

O treinamento da consciência fonológica ocorreu na própria escola da criança, porém fora do horário das aulas. Esse treinamento se deu em aproximadamente dois meses, sendo três sessões por semana, com duração em torno de 30 minutos com cada criança. As tarefas realizadas pelas crianças foram previamente descritas na seção Instrumentos. As crianças do grupo controle realizaram atividades no computador não relacionadas à leitura e à escrita (jogos, programas de desenho, etc.), pelo mesmo período de tempo que as crianças dos grupos experimentais. Após o procedimento de treinamento, avaliamos novamente a consciência fonológica e o desenvolvimento da escrita das crianças que constituíram a nossa amostra final.

\section{RESULTADOS}

Como podemos observar, a Tabela 2 fornece as médias dos dois grupos experimentais e do grupo controle. As médias de todos os grupos aumentaram entre o pré-teste e o pós-teste, tanto para a 
escrita quanto para a consciência fonológica. No entanto, podemos notar que as maiores diferenças entre os resultados do pré-teste e do pós-teste aconteceram nos grupos experimentais.

\section{TABELA 2}

Média e desvio-padrão dos grupos no pré-teste e no pós-teste.

\begin{tabular}{crrrr|r|r|r|r}
\hline & \multicolumn{2}{|c|}{ Grupo I } & \multicolumn{2}{c|}{ Grupo II } & \multicolumn{2}{c}{ Grupo III } \\
\hline Escrita & & Média & D.P & Média & D.P & Média & D.P \\
\hline & Pré-teste & 0 & 0 & 0 & 0 & 0 & 0 \\
Pós-teste & 6 & 4,08 & 4,29 & 2,69 & 0,5 & 0,55 \\
\hline Consc. Fonol. & Média & D.P. & Média & D.P. & Média & D.P. \\
\hline Pré-teste & 6 & 3,46 & 5,86 & 2,54 & 5,33 & 3,77 \\
& Pós-teste & 8,86 & 1,77 & 9 & 2,45 & 6 & 3,41 \\
\hline
\end{tabular}

Obs.: Grupo I - treino com computador; Grupo II - treino com cartões; Grupo III - controle

Lista de palavras ditadas:

$\begin{array}{lllll}\text { borboleta } & \text { molecada } & \text { gato } & \text { rã } & \text { sato } \\ \text { sacola } & \text { mão } & \text { jato } & \text { pá } & \text { zato }\end{array}$

Antes de compararmos estatisticamente as médias dos nossos grupos, optamos por transformar seus escores em sua contrapartida logarítmica. Adotamos esse procedimento porque, em amostras pequenas, como a nossa, é geralmente difícil obter uma distribuição normal. Assim, a conversão dos escores em seus logaritmos serviu para tornar nossa distribuição mais próxima de uma distribuição normal e permitiu-nos o uso de testes paramétricos. Desse modo, convertemos todos os escores (pré-teste e pós-teste) dos grupos em seu logaritmo na base dez, conforme a seguinte fórmula: $\log _{10}(x+1)$.

Uma das primeiras comparações de interesse em nosso trabalho é observar se os grupos experimentais diferiram de forma estatisticamente significativa do grupo controle no pós-teste. Nessa análise utilizamos um teste Tpara amostras independentes em que os grupos experimentais, em conjunto, foram comparados ao grupo controle. Obtivemos um resultado significativo, tanto para a escrita $T(1,18)=4,77$ para $p \leq 0,05$, quanto para a consciência fonológica $T(1,18)=2,60$ para $p \leq 0,05$. 
Uma outra comparação de interesse é entre os escores de um mesmo grupo no pré-teste e no pós-teste, pois existe a possibilidade de que esse aumento possa ser atribuído ao mero acaso e não à nossa intervenção. Nessas análises, utilizamos testes $T$ para medidas repetidas ao compararmos os resultados do pré-teste e do pós-teste de um mesmo grupo. Para ambos os grupos experimentais, obtivemos diferenças estatisticamente significativas entre o pré-teste e o pósteste, tanto na escrita quanto na consciência fonológica. Para o primeiro grupo experimental (estimulação com o computador), obtivemos $T(1,6)=5,99$ para $p \leq 0,05$ na escrita e $T(1,6)=2,67$ para $p \leq 0,05$ na consciência fonológica. Para o segundo grupo experimental (estimulação com cartões), obtivemos $T(1,6)=8,87$ para $p \leq 0,05$ na escrita e $T(1,6)=2,80$ para $p \leq 0,05$ na consciência fonológica. Já no grupo controle, como esperado, as diferenças não foram estatisticamente significativas, $T(1,5)=2,24$ para $p>0,05$ na escrita e $T(1,5)=0,61$ para $p>0,05$ na consciência fonológica.

Uma vez observado que o nosso treinamento foi efetivo, cabenos perguntar se existiu alguma diferença estatisticamente significativa entre os tratamentos empregados nos dois grupos experimentais. Para respondermos a essa pergunta, utilizamos um teste $T$ para amostras independentes e comparamos os escores dos dois grupos no pós-teste. Não obtivemos nenhuma diferença estatisticamente significativa entre os grupos $(T(1,12)=0,5$ para $p>0,05$ e $T(1,12)=0,05$ para $p>$ 0,05 para a escrita e a consciência fonológica, respectivamente). Evidenciou-se, dessa forma, que ambos os tratamentos experimentais foram igualmente eficazes.

Essas análises nos dão bons indícios para concluir que a intervenção na consciência fonológica foi efetiva, fazendo com que os grupos experimentais se desenvolvessem melhor, tanto na escrita quanto na consciência fonológica, em comparação ao grupo controle. No entanto, essas análises não nos dão uma estimativa do quão forte foi o papel do treinamento no desenvolvimento dessas habilidades. Para que pudéssemos ter alguma informação a respeito disso, deveríamos apresentar alguma estimativa da magnitude do efeito (em 
inglês, effect size) de nossa intervenção. Esse tipo de dado é importante por duas razões: primeiro, porque ele nos dá uma estimativa de quão forte foi o papel do treinamento em nosso experimento e segundo, porque a magnitude do efeito serve de estimativa para que estudos futuros possam calcular, previamente, o tamanho de suas mostras, garantindo um poder estatístico adequado a suas análises (COHEN, 1977; 1994).

Desse modo, decidimos calcular a magnitude do efeito de nossa intervenção de acordo com os procedimentos sugeridos por Boresntein, Rothstein e Cohen (2001). No caso do teste Tpara medidas repetidas (que foi o teste utilizado por nós para compararmos os escores dos grupos no pré-teste e no pós-teste), a magnitude do efeito ( $d$ ) pode ser calculada dividindo-se a diferença entre as duas médias (pré-teste e pós-teste) pelo desvio-padrão da diferença entre essas médias. Assim, obtivemos para o grupo I (treinamento no computador) um $d=2,27$, representando o efeito do treinamento na consciência fonológica no desenvolvimento da escrita, e um $d=1,01$, para a intervenção na consciência fonológica. No caso do grupo II (treinamento tradicional), obtivemos um $d=3,35$, representando o efeito do treinamento na consciência fonológica no desenvolvimento da escrita, e um $d=1,06$, para a intervenção na consciência fonológica. É importante ressaltar que, de acordo com os valores convencionalizados por Cohen (1977; 1994; BORESNTEIN et al, 2001), uma magnitude do efeito (d) de 0,8 já pode ser considerada grande. Sendo assim, podemos nos sentir à vontade para concluir que nossa intervenção foi bastante efetiva, pois nossos valores $d$ superaram os valores propostos por Cohen, especialmente no que diz respeito ao desenvolvimento da escrita.

\section{DISCUSSÃO}

Como salientamos anteriormente, os nossos objetivos no presente trabalho foram: 1) levar a cabo um programa de treinamento da consciência fonológica e observar as possíveis alterações na escrita; 
2) avaliar se o computador é um dispositivo eficaz para ser utilizado na estimulação da consciência fonológica; e 3) prover o leitor de algumas estimativas do quão forte foi o efeito do treinamento.

No que diz respeito ao primeiro objetivo, nossas análises evidenciaram que o programa de treinamento empregado foi eficaz ao promover o desenvolvimento da escrita. É importante assinalar que, além do próprio controle experimental adotado, a metodologia de ensino da escola, no que tange à leitura e à escrita, diferia-se da metodologia empregada em nosso treinamento, o que diminui a possibilidade de o ensino escolar ter afetado os resultados desse estudo.

De uma forma geral, os resultados encontrados nesta pesquisa servem-nos de indício de que talvez seja bastante salutar que atividades relacionadas à estimulação da consciência fonológica venham a ser empregadas como atividades curriculares na pré-escola. Principalmente se, em algum momento, as crianças são levadas a pensar explicitamente sobre a relação dos sons da linguagem oral com alguns componentes da linguagem escrita. Nesse sentido, concebemos a consciência fonológica como uma habilidade metacognitiva que guarda uma relação interativa com o desenvolvimento da escrita. Cabe relembrar que essa posição não é consensual, embora venha sendo adotada pela maioria dos investigadores.

Nosso segundo objetivo foi o de avaliar se o computador é um dispositivo eficaz para ser utilizado na estimulação da consciência fonológica. Ao compararmos os grupos experimentais, observamos que não foram encontradas diferenças estatisticamente significativas entre eles. Desse modo, podemos concluir que o treinamento por meio do computador é tão eficaz quanto o treinamento por meio do uso de cartões. Esse resultado é interessante, pois aponta para a possibilidade de programas de treinamento similares a esse poderem ser implementados em pré-escolas sem a necessidade do uso de recursos dispendiosos como o computador, embora o uso desse instrumento possa ter outras implicações prático-pedagógicas (WEISS; CRUZ, 1998). 
No que se refere ao último objetivo, a estimação da magnitude do efeito de nossa intervenção permitiu-nos concluir que o treinamento produziu uma melhora considerável tanto na consciência fonológica das crianças quanto na sua escrita. Afinal, todas as nossas estimativas ficaram além dos valores convencionalizados por Cohen (1977; 1994; BORESNTEIN et al, 2001).

À guisa de conclusão, assim como outras investigações que já foram realizadas nesta área, este estudo demonstra a importância das habilidades metalingüísticas nas etapas iniciais da aprendizagem da escrita e, assim como outros, propõe que o estímulo dessas habilidades, mais especificamente, da consciência fonológica, seja incluído no currículo de Educação Infantil. A esse respeito, Defior (1994) e Dominguez (1996) salientam que, assim sucedendo, haveria uma facilitação tanto no processo de identificação das crianças com risco de fracasso devido à pouca conscientização dos sons das palavras quanto na intervenção, pois essa seria imediata à detecção das crianças que apresentam esse tipo de dificuldade. Portanto, antes que essas crianças pudessem vir a expressar um desempenho ruim na aprendizagem da escrita, elas seriam estimuladas a percorrer um caminho oposto. Trata-se de uma questão preventiva de suma importância, pois sabemos dos percalços encontrados nos caminhos da remediação.

É importante ressaltar, no entanto, que o fato de o resultado desse estudo sugerir a importância da consciência fonológica no desenvolvimento da escrita, de forma alguma pretende reduzir ou minimizar a possível contribuição de outras habilidades ou fatores na aquisição da escrita. A consciência fonológica contribui para o desenvolvimento dessa habilidade, mas não de forma isolada e única. Pesquisas recentes, por exemplo, evidenciam a importância da contribuição dos processos subjacentes à velocidade de nomeação para o desenvolvimento da leitura e da escrita (WOLF; BOWERS, 1999; WOLF; BOWERS; BIDDLE, 2000). No que se refere a nossa própria língua, o trabalho de Guaraldo e Cardoso-Martins (2005) aponta que tanto a consciência fonológica quanto os processos 
subjacentes à velocidade de nomeação contribuem, de forma independente, para o desenvolvimento dessas habilidades. O estudo de Lepola, Poskiparta, Laakkonen e Niemi (2005) também evidencia a importância dos processos fonológicos e dos processos subjacentes à velocidade de nomeação para o desenvolvimento da leitura e da escrita, mas ressalta, conjuntamente, a importância dos processos motivacionais. Dessa forma, além da consciência fonológica, estudos sugerem que outras habilidades parecem ser importantes na aquisição da leitura e da escrita. Pesquisar essa possibilidade é de fundamental importância, pois sabemos o quanto o desenvolvimento das habilidades de ler e escrever é indispensável na formação de um ser humano pleno, crítico e agente de transformações sociais.

\section{NOTAS}

${ }^{1}$ Corresponde à vogal ou ao ditongo e quaisquer consoantes seguintes na sílaba.

${ }^{2}$ Corresponde à consoante ou ao o grupo consonantal inicial.

${ }^{3}$ As sílabas são demarcadas pelo fluxo acústico, manifestam-se na fala como unidades discretas.

${ }^{4}$ Os fonemas produzidos na fala são acusticamente inseparáveis devido à coarticulação. De acordo com Liberman, os fonemas não se manifestam na fala como unidades discretas, mas são misturados e integrados uns aos outros, existindo como unidades separadas apenas em um nível abstrato, psicológico (citado em Cardoso-Martins, 1996).

${ }^{5}$ É importante assinalar que utilizamos esses níveis apenas para classificar as crianças em grupos de acordo com a sua de habilidade na escrita, mantendonos neutros, portanto, quanto às possíveis interpretações teóricas desses. 


\section{REFERÊNCIAS BIBLIOGRÁFICAS}

ASYMETRIX CORPORATION. Toolbook II Version 5.01, 1996.

BARRERA, L. La conciencia fonológica silábica y el aprendizaje de la lengua escrita. Lectura y Vida, v.4, p. 20-25, 1999.

BARRERA, L. Consciência metalingüística e alfabetização: um estudo com crianças da primeira série do ensino fundamental. Psicologia: Reflexão e Crítica, v.16, p. 491-502, 2003.

BOWEY, J. Phonological sensitivity in novice readers and nonreaders. Journal of Experimental Child Psychology, v.58, p. 134-159, 1994.

BRYANT, P.; BRADLEY, L. Problemas de leitura na criança. Porto Alegre: Artes Médicas, 1987.

BRYANT, P.; MACLEAN, M.; BRADLEY, L.; CROSSLAND, J. Rhyme and alliteration, phoneme detection and learning to read. Developmental Psychology, v.26, p. 429-438, 1990.

BORESNTEIN, M.; ROTHSTEIN, H.; COHEN, J. Power and Precision 2. Software produzido pela Biostat, Inc., 2001.

BYRNE, B. Treinamento da consciência fonêmica em crianças pré-escolares: por que fazê-lo e qual o seu efeito? In: Cardoso-Martins, C. Consciência fonológica e alfabetização. Petrópolis: Vozes, 1995.

CAPOVIlla, F.; CAPOVILlA, A. Efeitos do treino de consciência fonológica em crianças com baixo nível sócio-econômico. Psicologia: Reflexão e Critica, v.13, p. 125-145, 2000.

CARDOSO-MARTINS, C. A consciência fonológica e a aprendizagem inicial da leitura e da escrita. Cadernos de Pesquisa, v.76, p. 41-49, 1991.

CARDOSO-MARTINS, C.; DUARTE, G. Preschool children's ability to disregard meaning and focus attention on the phonological properties of speech: some discrepant findings. British Journal of Developmental Psychology, v. 12, p. 429-438, 1994.

CARDOSO-MARTINS, C. Consciência fonológica e alfabetização. Petrópolis: Vozes, $1995 \mathrm{a}$.

CARDOSO-MARTINS, C. Sensitivity to rhymes, syllables and phonemes in literacy acquisition in Portuguese. Reading Research Quarterly, v.30, p. 808-828, 1995 b. 
CARDOSO-MARTINS, C. A sensibilidade à rima e ao fonema e a aquisição da leitura em crianças normais e em individuos com síndrome de Down: um estudo correlacional. Tese apresentada ao Departamento de Psicologia da Universidade Federal de Minas Gerais, como parte dos requisitos para o Concurso de Professor Titular, 1996.

CASTLES, A.; HOLMES, V.; NEATH, J.; KINOSHITA, S. How does orthographic knowledge influence performance on phonological awareness tasks? Quarterly Journal of Experimental Psychology, v. 56, p. 445-467, 2003.

CASTLES, A.; COLTHEART, M. Is there a causal link from phonological awareness to success in learning to read? Cognition, v.91, p. 77-111, 2004.

CHEN, X.; ANDERSON, C.; LI, W.; HAO, M.; WU, X.; SHU, H. Phonological Awareness of Bilingual and Monolingual Chinese Children. Journal of Educational Psychology, v. 96, p. 142-151, 2004.

COHEN, J. Statistical power analysis for the behavioral sciences. New York: Academic Press, 1977.

COHEN, J. The earth is round ( $<$.05). American Psychologist, v.49, p. 997-1003, 1994.

DEFIOR, S. La conciencia fonológica y la aquisición de la lectoescritura. Infancia $y$ aprendizaje, v.67, p. 91-113, 1994.

DEFIOR, S. Una classificación de las tareas utilizadas en la evaluación de las habilidades fonológicas y algunas ideas para su mejora. Infancia y Aprendizaje, v.73, p. 49-63, 1996.

DOMINGUEZ, A. B. Evaluación de los efectos a largo plazo de la enseñanza de habilidades de análisis fonológico en el aprendizaje de la lectura y de la escritura. Infancia y Aprendizaje, v. 76, p. 83-96, 1996.

EDWARDS, J.; WALLEY, A.; BALL, K. Phonological, visual and temporal processing in adults with and without reading disability. Reading and Writing: An Interdisciplinary Journal, v. 16, p. 737-758, 2003.

FERREIRO, E.; TEBEROSKY, A. A psicogênese da lingua escrita. Porto Alegre: Artes Médicas, 1986.

GOSWAMI, U.; BRYANT, P. Phonological skills and learning to read. Hillsdale: Erbaum, 1990.

GUARALDO, C.; CARDOSO-MARTINS, C. A hipótese do duplo-déficit e o desenvolvimento da leitura e da escrita. Anais do $V$ Congresso Brasileiro de Psicologia do Desenvolvimento, 2005. 
LEPOLA, J.; POSKIPARTA, E.; LAAKKONEN, E.; NIEMI, P. Development of and relationship between phonological and motivational processes and naming speed in predictig word recognition in grade 1. Scientific Studies of Reading, v. 9, p. 367-399, 2005.

LIBERMAN, I. Segmentation of the spoken word and reading acquisition. Bulletin of the Orton Society, v. 23, p. 65-77, 1973

MALUF, R.; BARRERA, S. Consciência fonológica e linguagem escrita em préescolares. Psicologia: Reflexão e Crítica, v. 10, p. 125-145, 1997.

MANRIQUE, A.; DE SIGNORINI, A. Del habla a la escritura: la consciência linguística como una forma de transición natural. Lectura y Vida, v. 9, p. 5-9, 1988.

MANN, V. Longitudinal prediction and prevention of early reading difficulty. Annals of Dyslexia, v. 34, p. 117-136, 1984.

MANN, V.; LIBERMAN, I. Phonological awareness and verbal short-term memory. Journal of Learning Disabilities, v.17, p. 592-599, 1984.

MANN, V.; WIMMER, H. Phoneme awareness and pathways to literacy: a comparison of German and American children. Reading and Writing, v. 15, p. 653-682, 2002.

MASSINI-CAGLIARI, G.; CAGLIARI, L. Diante das Letras: a escrita na alfabetização. Campinas: Mercado de Letras; Associação de Leitura do Brasil (ALB); FAPESP, v. 1, p. 238, 1999.

MORAIS, J.; ALEGRIA, J.; CONTENT, A. The relationships between segmental analysis and alphabetic literacy: an interactive view. Cabiers de Psychologie Cognitive, v.7, p. 1-24, 1987.

MORAIS, J. A arte de ler. São Paulo: Editora da Universidade Estadual Paulista, 1996.

PENNINGTON, B. Understanding the comorbidity of dyslexia. Annals of Dyslexia, v. 53, 2003.

ROAZZI, A.; DOWKER, A. Consciência fonológica, rima e aprendizagem da leitura. Psicologia: Teoria e Pesquisa, v.1, p. 31-55, 1989.

SNOWLING, M.; HULME, C. Developmental dyslexia and language disorders. In G. Blanken, J. Dittmann, H. Grimm, J. C. Marshall, e C.-W. Wallesch (Eds.). Linguistic disorders and pathologies: an international handbook, p. 724-732. New York: de Gruyter, 1993. 
STUART, S. Phonemic analysis and reading development: some current issues. Journal of Research in Reading, v.28, p. 39-49, 2005.

TORGESEN, J.; WAGNER, R.; RASHOTTE, C.; BURGESS, S.; HECHT, S. Contributions of phonological awareness and rapid automatic naming ability to the growth of word-reading skills in second - to fifth - grade children. Scientific Studies of Reading, v. 1, p. 161-185, 1997.

VERNON, S. Escritura y conciencia fonológica en niños hispano-parlantes. Infancia y Aprendizaje, v.81, p. 105-120, 1998.

WAGNER, R.; TORGESEN, J. The nature of phonological processing and its causal role in the acquisition of reading skills. Psychological Bulletin, v.101, p. 192-212, 1987.

WAGNER, R.; TORGESEN, J.; LAUGHON, P.; SIMMONS, S.; RASHOTTE, C. Development of young reader's phonological processing abilities. Journal of Educational Psychology, v.85, p. 83-103, 1993.

WAGNER, R.; TORGESEN, J.; RASHOTTE, C. Development of reading-related phonological processing abilities: Evidence of bidirectional causality from a latent variable longitudinal study. Developmental Psychology, v. 30, p. 73-87, 1994.

WAGNER, R.; TORGESEN, J.; RASHOTTE, C.; HECHT, S.; BARKER, T.; BURGESS, S.; DNAHUE, J.; GARON, T. Changing Relations Between Phonological Processing Abilities and Word-Level Reading as Children Develop From Beginning to Skilled Readers: A 5-Year Longitudinal Study. Developmental Psychology, v. 33, p. 468-479, 1997.

WEISS, A.; CRUZ, M. A informática e os problemas de aprendizagem. Rio de Janeiro: DP\&A, 1998.

WOLF, M.; BOWERS, P. The double-deficit hypothesis for the developmental dyslexias. Journal of Educational Psychology, v. 91, p. 415-438, 1999.

WOLF, M.; BOWERS, P.; BIDDLE, K. Naming-speed processes, timing, and reading: a conceptual review. Journal of Learning Disabilities, v. 33, p. 387-407, 2000. 